\title{
Endoplasmic reticulum aminopeptidase protein 1 and Behçet's syndrome
}

\author{
Beuy Joob ${ }^{1}$ (D) Viroj Wiwanitkit ${ }^{2}$
}

Received: 17 August 2019 / Accepted: 21 August 2019 / Published online: 31 August 2019

c) Società Italiana di Medicina Interna (SIMI) 2019

Dear Editor, we read the publication on "Distribution of rs17482078 and rs27044 ERAP1 polymorphisms in a group of Italian Behçet's syndrome (BS) patients: a preliminary case-control study" with a great interest [1]. Padula et al. concluded that "our data show a stronger association of rs 17482078 with BS compared to rs 27044 by means of case-control genetic analysis and bioinformatics prediction of protein structure change [1]". We would like to share ideas and discuss on the effect of the studied genetic variants. Indeed, this observation is explainable by the molecular change. Regarding rs17482078 (NG_027839.1:g.35983G>A) and rs27044 (NG_027839.1:g.35997C $>\mathrm{G}$ ), the main change is at a nucleic acid in each variant. Based on the molecular weight alteration calculation as mentioned in the previous literatures [2-4], the change in rs 17482078 and rs27044 is equal to -16 and $+40.02 \mathrm{~g} / \mathrm{Mol}$. Therefore, the expression process in rs27044 is more difficult and the stronger association with BS can be expected in rs 17482078. This pathophysiological process is explainable in the same way as those described in clinical association between genetic variants and other medical disorder [2-4].

Here, the author uses calculation technique to show the molecular weight alteration of rs 17482078 (NG_027839.1:g.35983G >A) and rs 27044 (NG_027839.1:g.35997C >G) nucleotide changes and can further explain why the expression process in rs27044 is more difficult and the stronger association with BS can be expected in rs17482078. This result can confirm the finding by Padula et al. [1]. The advantage of genetic polymorphism study for the patients with BS might be proposed. As noted by Krause and Weinberger, a novel genetic biomarker test is a useful biomarker for monitoring of $\mathrm{BD}$ severity during

\footnotetext{
Beuy Joob

beuyjoob@hotmail.com

Sanitation 1 Medical Academic Center, Bangkok, Thailand

2 Dr DY Patil University, Pune, India
}

active phase [5]. It can add to the classical immunological test for predicting the severity of clinical manifestation [5]. If a practitioner selects to use genetic polymorphism to help monitor the patient with BS, rs17482078 ERAP1 polymorphism test should be included.

\section{Compliance with ethical standards}

Conflict of interest The authors declare that they have no conflict of interest.

Statements on human and animal rights This article does not contain any studies with human participants or animals performed by any of the authors.

Informed consent For this type of study formal consent is not required.

\section{References}

1. Padula MC, Leccese P, Pellizzieri E, Padula AA, Gilio M, Carbone T, Lascaro N, Tramontano G, Martelli G, D’Angelo S (2019) Distribution of rs17482078 and rs27044 ERAP1 polymorphisms in a group of Italian Behçet's syndrome patients: a preliminary case-control study. Int Emerg Med 14:713-718

2. Yasri S, Wiwanitkit V (2018) Caspase recruitment domain-containing protein 8 rs2043211 polymorphism and cardiovascular disease susceptibility. Anatol J Cardiol 20(6):368

3. Yasri S, Wiwanitkit V (2018) Having rs1042636C677T calciumsensing receptor polymorphism: increased or decreased risk for nephrolithiasis? Saudi J Kidney Dis Transpl 29(3):743-744

4. Joob B, Wiwanitkit V (2016) SD11B1 rs846908 polymorphisms and tacrolimus concentrations: quantum chemical analysis and implication in patients with renal transplantation. J Nephropharmacol 6(1):19-20

5. Krause I, Weinberger A (2008) Behçet's disease. Curr Opin Rheumatol 20(1):82-87

Publisher's Note Springer Nature remains neutral with regard to jurisdictional claims in published maps and institutional affiliations. 